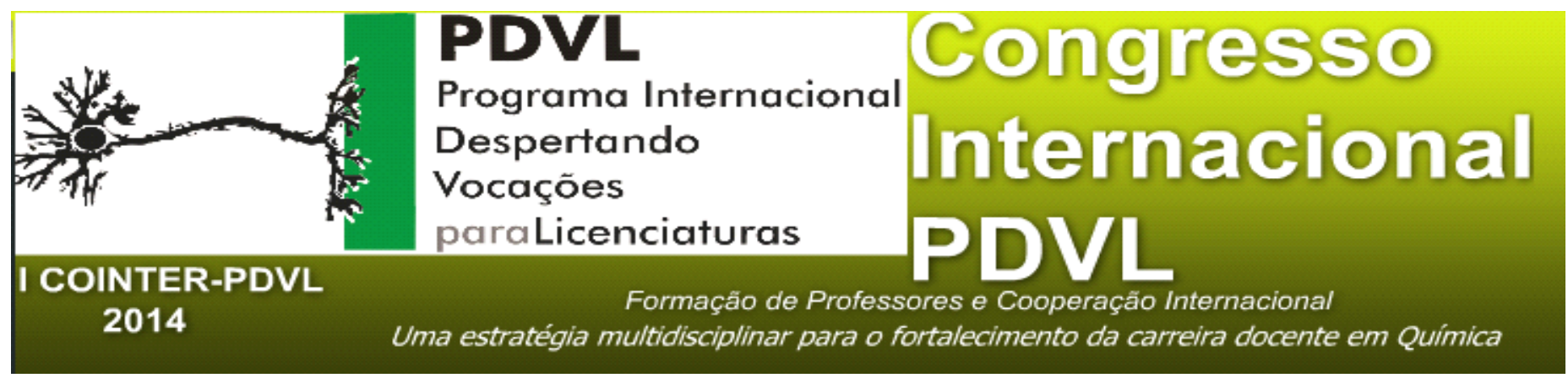

\title{
AVALIAÇÃO NO ENSINO DAS CIÊNCIAS DA NATUREZA: AS ORIENTAÇÕES NACIONAIS E PESQUISAS NA ÁREA
}

\author{
Apresentação: Comunicação Oral
}

Inês Girlene dos Santos Monteiro ${ }^{1}$; Eliemerson de Souza Sales ${ }^{2}$; Ana Maria da Cunha Rego ${ }^{3}$; Francisca Maria Silva Miranda ${ }^{4}$; Kilma da Silva Lima Viana ${ }^{5}$

\section{Resumo}

Esse artigo trata sobre as orientações nacionais para o ensino e avaliação das ciências da Natureza. Refere-se a uma pesquisa tipo bibliográfica realizada nos $\mathrm{PCN}+\mathrm{e}$ uma releitura dos artigos publicados pelo Grupo de estudos e Pesquisas em ensino de Ciências GEPEC. Seu objetivo é fazer uma reflexão dos caminhos que são orientados pelos documentos oficias e como tem sido a realidade em sala de aula. Seus resultados apontam para uma discordância entre as orientações e pesquisas na área. Destaca a importância de se ter um olhar mais atento para essas área, na perspectiva de reorientar os caminhos que vem trilhando.

Palavras-Chave: Avaliação, Ensino de Química e Física, Orientações Nacionais; GEPEC.

\section{Introdução}

Neste trabalho apresentaremos um estudo bibliográfico sobre avaliação e ensino das Ciências da Natureza, especialmente, Química e Física. A importância desses estudos é compreender como as orientações nacionais e pesquisas na área estão tratando esse tema e como ele está sendo desenvolvido na prática.

O ensino e avaliação nessa área, historicamente sempre esteve atrelado com práticas relacionadas à abordagens tradicionais. A ênfase pela memorização e reprodução do conteúdo sempre foi foco nas salas de aula. A avaliação, por consequência também, estando relacionada às Primeiras Gerações da Avaliação (GUBA; LINCOLN, 1989), que

\footnotetext{
1 Licencianda em Química/IFPE/ Grupo de Estudos e Pesquisas em Ensino de Ciências/inesmonteiro777@gmail

2 Licenciando em Química/IFPE/Grupo de Estudos e Pesquisas em Ensino de

Ciências/eliemersonsales@gmail.com

3 Licencianda em Pedagogia/UFPE/Grupo de Estudos e Pesquisas em Ensino de Ciências/anacunha11@hotmail.com

4 Pedagoga/IFPE/Grupo de Estudos e Pesquisas em Ensino de

Ciências/francisca.miranda@@vitoria.ifpe.edu.br

5 Professora da Licenciatura em Química/IFPE/Grupo de Estudos e Pesquisas em Ensino de

Ciências/kilma.viana@vitoria.ifpe.edu.br
} 
primava pela memorização e quantificação da aprendizagem.

Dessa forma, faz-se necessário um olhar mais aprofundado para essa área, na perspectiva de propor mudanças e refletir sobre a realidade que está posta. Esperando contribuir, com esse trabalho, ara a discussão da temática e reflexão.

\section{Fundamentação Teórica}

Para falarmos sobre a avaliação no ensino das Ciências da Natureza, faz-se necessário refletir sobre a sua evolução histórica. Segundo Guba e Lincoln (1989), as idéias da avaliação passaram por uma evolução ao longo do tempo. Essa evolução pode ser mais bem entendida se for olhada a partir de Gerações.

A Primeira Geração da Avaliação (Chamada de Geração da Medida) está relacionada à quantificação da aprendizagem. Nessa Geração, medida e avaliação se confundiam. O foco era a reprodução do conteúdo aprendido em sala de aula.

A Segunda Geração traz um aspecto qualitativo para o processo avaliativo: a Descrição. Também chamada de Geração da Descrição, tinha o objetivo de descrever os pontos fortes e fracos do processo de ensino-aprendizagem em relação aos objetivos préestabelecidos. A Terceira Geração (Geração do Juízo de Valor), buscava superar as lacunas das primeiras Gerações e se preocupa com a construção do conhecimento. A avaliação teria o objetivo de julgar o valor e mérito do objeto avaliado para a tomada de decisão.

Finalmente, a Quarta Geração da Avaliação. Essa geração, também chamada de Geração da Negociação, tinha os acordos e o consenso como carro-chefe. Nela, as responsabilidades pelo processo e pelas tomadas de decisões eram compartilhadas entre os envolvidos (professor e estudantes). Buscava a autonomia dos estudantes e a qualificação do processo de construção do conhecimento.

\section{Metodologia}

Esse artigo apresenta uma pesquisa bibliográfica sobre as orientações nacionais (PCN+) e pesquisas do Grupo de Estudos e Pesquisas em Ensino de Ciência (GEPEC) acerca do ensino e avaliação em Química e Física. Sua abordagem é qualitativa, realizada da seguinte maneira: inicialmente, foram observados os aspectos relacionados ao ensino da Química e da Física, o conhecimento químico e físico, a forma que o conhecimento químico e físico são orientados e suas relações com a realidade da sala de aula de acordo com as pesquisas na área. Por fim, são observadas as orientações para a avaliação para 
essa área.

\section{Resultados e Discussões}

Observa-se o quanto o conhecimento Químico é essencial para a formação do cidadão, o conhecimento Químico também é de suma importância. A Química está em constante interação com o individuo. Isso acontece por diversos meios, desde os remédios até o inseticida que utilizamos. Somos rodeados pela Química e muitas vezes não nos damos conta. Muitas vezes porque a nossa educação em Química não nos permitiu ver.

Apesar desse conhecimento Químico parecer tão distante da vida cotidiana, como se ele fosse algo apenas encontrado em laboratório, ele está a todo momento em contato direto conosco. Aqueles elementos químicos que os professores teimam em ensinar usando a tabela Periódica e que muitas vezes os alunos só aprendem os símbolos, são elementos encontrados na Natureza e fazem parte do nosso dia-a-dia.

Essa base natural da Química, que muitas vezes são desvalorizadas no ensino, e que, com o investimento em pesquisas na área, vai se transformando em algo mais sofisticado, precisaria ser foco também do ensino da Química, que vai desde as plantas que servirão de matéria-prima para medicamentos até os próprios medicamentos que fazem parte de nossa vida, mas que é produzido através de pesquisas científicas sofisticadas.

Como a Química é uma ciência que, por muitos anos, ficou "misturada" com crenças, um ponto de contato entre o conhecimento popular e científico, foi preciso um investimento grande em pesquisas na área para delimitar essa separação, pois, muitas vezes, as crenças populares só contribuíram para distorcer e comprometer ainda mais a visão dessa ciência e dos seus cientistas. A exemplo disso tivemos os alquimistas. $\mathrm{Na}$ verdade, falar de Química é lembrar dos alquimistas. Que foram vistos como feiticeiros, mágicos e não como pensadores.

Essa visão distorcida da Química e dos cientistas ocorre até os dias atuais e reforçando a visão distorcida temos a mídia que, a todo momento, relaciona o químico como um cientista maluco que passa a vida explodindo laboratórios, com sua bata branca e queimada. Além disso, os PCN alertam que as informações veiculadas pela mídia, normalmente são exageradas ou errôneas e, nos tempos atuais, transformaram a Química como a vilã do final do século, porque é através dela que se desenvolvem os poluentes.

O que complica ainda mais essa situação é o fato de que, por mais que esteja em "moda" discutir a ação dos poluentes químicos na Natureza, o aquecimento global, o 
efeito estufa, entre outros, na escola, esse conhecimento não é contextualizado. Essas temáticas são tratadas de forma, normalmente, isoladas da aula de Química, por exemplo, numa Feira de Ciências. Assim, esse conhecimento se restringe à transmissão de informações, memorização de fórmulas, de valores, de símbolos, de dados estatísticos.

O mais incrível é que nos últimos 50 anos, o conhecimento Químico incorporou novas formas e abordagens, em escala mundial. Entretanto, no Brasil, a Química na escola permanece com os mesmos modelos. Salas de aulas com alunos passivos, observando o professor demonstrar suas fórmulas ou experimentos que, assim como no ensino da Física, também apenas comprovam a teoria (ANDRADE; SALES; LIMA, 2013). Confirmam que os cientistas estavam certos. $\mathrm{E}$ as aulas de laboratórios se resumem ou a shows de cores, odores e luz ou a cumprimentos de normas ou roteiros. Esses roteiros dão pistas para que os alunos possam "chegar na teoria" (SALES, MONTEIRO; LIMA, 2013). Verificar que a ciência é baseada em comprovações.

Para isso, os professores perdem horas testando os experimentos em casa ou nos laboratórios, longe de seus alunos, controlando todas as variáveis para que tudo dê certo e a teoria não seja questionada. A ênfase nas aulas são as propriedades periódicas dos elementos e não os elementos no mundo, seus significados, sua utilização, as consequiências dessa utilização, a ética na ciência. Questões que façam sentido para o aluno estudar.

A aprendizagem em Química nas escolas está longe de representar um momento de descoberta. Onde alunos interagem com outros e buscam soluções de um problema através de levantamento de hipóteses, tentativas e erros. O professor também, que poderia ser um grande orientador e mediador nesse processo, não faz esse papel. Pelo contrário. Aluno ainda não se aventura, não tem espaço para dúvidas, apenas as previstas no plano de aula.

Segundo os PCN (BRASIL, 2002), o roteiro nos laboratórios muitas vezes é tão informativo que tira do professor o papel de coordenar o processo. A autonomia do aluno, nessa abordagem, é quase nula e o aluno raramente é solicitado a fazer julgamentos sobre o que está estudando, mesmo sendo a Química uma ciência que traz, de forma intrínseca, questões éticas de grande repercussão.

O ensino da Química deve possibilitar tanto a compreensão de seus conceitos, quanto as aplicações tecnológicas e suas implicações no meio ambiente e na vida do indivíduo e da sociedade. E essa importância justifica a sua presença no Ensino Médio. Então, se esse olhar para a Química não existe no Ensino Médio, qual seria sua 
importância, afinal? Por que os alunos precisariam estudar tantos elementos e fazer tantos cálculos e perderem suas noites de sono aprendendo (ou decorando) a Química?

São perguntas para refletir em um momento tão crucial para a humanidade, quando já temos no planeta mais de 6 bilhões de habitantes e todos com necessidades que a sociedade moderna criou, mas que fazem parte de suas vidas. Necessidades que muitas e muitas vezes prejudicam a si mesmos e que, com um pouco de conhecimento da Química, poderiam contribuir para sua melhoria.

Discutir, então a Química e suas questões mais atuais, que estão diretamente ligadas às vidas dos alunos e da sociedade como um todo é o papel de todo professor de Química que estão nas salas de aula do mundo inteiro. O Brasil não pode se excluir desse papel. É preciso que as práticas nas salas de aula formem pessoas críticas, que saibam viver em seu mundo e não apenas reproduzir conhecimentos historicamente construídos. Práticas que não se limitem a práticas sofisticadas em laboratórios, que a sala de aula sejam o espaço também do ensino e da natureza experimental da Química (SALES; MONTEIRO; LIMA, 2013; ANDRADE; SALES; LIMA, 2013; MONTEIRO; SALES; LIMA, 2013).

Esses mesmos conhecimentos, que passaram por momentos históricos se reconstruíram para chegar a nossas salas de aula. E é na escola que o conhecimento pode e deve ser reconstruído, por mentes jovens e cheias de vida. Há de se perguntar, o que fizeram com a curiosidade natural das crianças? "O ser humano, na luta pela sua sobrevivência, sempre teve a necessidade de conhecer, entender e utilizar o mundo que o cerca (BRASIL, 2002, p. 32). Parece que a escola, local de reflexão e construção do saber, passou a se configurar como algo nocivo à construção, à criação, à curiosidade.

Quando nossas crianças chegam à escola, os olhos brilham e nada a impede de perguntar, criticar e inventar. Mas com o passar dos alunos, o brilho no olhar vai diminuindo e a voz vai calando como se todo o desejo de saber tivesse sido sufocado nas práticas reprodutivistas e conservadoras. E essas práticas reprodutivistas pressupõem uma avaliação também dessa natureza, próprias da Primeira Geração da Avaliação (REGO; MONTEIRO; VIANA, 2014).

Assim a avaliação no ensino de Química é baseada em questões matematizadas, em que basta substituir valores para "acertar". Mas que acerto é esse afinal? O que o aluno aprendeu? A maioria dos exercícios avaliativos dessa área do saber se limita à verificação do que foi apresentado em sala pelo professor (SALAES; MONTEIRO; LIMA, 2013; SALES; LIMA, 2013). As listas de exercícios extensas, disponibilizadas aos alunos para 
treinamento e memorização, que não requerem do aluno aprofundamento dos estudos. As novas perspectivas da Avaliação (de Quarta Geração) propõem uma postura diferenciada, dialogada, mediadora (HOFFMAN, 2001), com abordagem baseadas em levantamento de hipótese e descobertas, de modo que a reprodução não seja mais considerada. Assim, a avaliação teria o objetivo de regular e reorientar o processo e não reproduzir.

Não queremos dizer que é sempre assim e nem estamos generalizando situações. Apenas tentando entender o papel do ensino da Química na vida de cada um de nossos alunos. É óbvio que o conhecimento Químico ensinado na escola é importante, quantas maravilhas já foram feitas a partir dele?! Muitas. O que defendemos aqui é que não é suficiente. Muito menos se foram mantidas as formas de avaliar baseadas na reprodução do conteúdo, quando o que faz é apenas responder a momentos estanques.

Dois aspectos são necessários destacar: o primeiro é que a Química fazer sentido para o aluno, e a segunda, é que a avaliação em Química precisa ir investigar a apropriação, a compreensão e a capacidade de relacionar os conceitos químicos com a vida cotidiana e com outras áreas do saber. Não é apenas do saber especializado e isolado que precisamos para viver e compreender o mundo. Precisamos estar no mundo, participar, fazer parte dele, decidir, transformar, e, para isso, o conhecimento na escola precisa ganhar uma nova dimensão.

É importante ressaltar que faz parte do ensino da Química possibilitar ao aluno a compreensão do processo de elaboração desse conhecimento, com seus avanços, erros e conflitos. A consciência de que o conhecimento científico é assim dinâmico e mutável ajudará o estudante e o professor a terem a necessária visão crítica da ciência. Não se pode simplesmente aceitar a ciência como pronta e acabada e os conceitos atualmente aceitos pelos cientistas e ensinados nas escolas como "verdade absoluta". (BRASIL, 2002, P. 32)

Dessa maneira, o conhecimento químico pode e deve permitir a construção de visão do mundo, mas para isso, o aluno que está nesse processo de construção pode se sentir participante, integrado ao conhecimento e agente de transformação. Mas se o conhecimento se mantém isolado em todos os momentos ou é contextualizado em situações especiais, como em uma Feira de Ciências, por exemplo, fica difícil conceber que esse conhecimento foi desenvolvido para compreender o mundo.

O Conhecimento Físico também é indispensável. Ele permite compreender a dinâmica do Universo. Possibilita a investigação dos mistérios da matéria e a criação de novos materiais, novas tecnologias. Diante disso, é peça chave na formação da cidadania, 
afinal, auxilia na análise e interpretação dos fenômenos da natureza que nos rodeiam.

As orientações para a formação de professores estão descritas nos PCN+ (2002, p.21) “é essencial que o conhecimento físico seja explicitado como um processo histórico, objeto de contínua transformação e associado às outras formas de expressão e produção humanas". Dessa forma, seu ensino precisa estar vinculado à realidade social. Precisa ser contextualizado e incluir discussões acerca de um "conjunto de equipamentos e procedimentos, técnicos ou tecnológicos, do cotidiano doméstico, social e profissional" (p.21).

Garantindo essa articulação com as questões práticas do mundo, o seu ensino promoverá uma visão mais ampla do universo e relações com o cotidiano, que muitas vezes nos passam despercebidos. Como se a Física só fosse possível ser entendida a partir de experimentos sofisticados em laboratórios, quando, pelo contrário, faz parte de nossa vida prática, muito deixada de lado nas nossas salas de aula. Historicamente, o ensino da Física sempre esteve atrelado a práticas conservadoras, em que são privilegiadas as apresentações de fórmulas, leis e conceitos de maneira isolada, mas que poderiam estar articulados com o mundo real dos estudantes.

O ensino dessa disciplina vem privilegiando assim "a teoria e a abstração, desde o primeiro momento, em detrimento de um desenvolvimento gradual da abstração que, pelo menos, parta da prática e de exemplos concretos" (BRASIL, 2002, p. 22). Essa postura em sala de aula reforça a ideia de que a Física é para cientistas. E apenas eles (os cientistas) estariam aptos a compreendê-la de maneira mais ampla. Aos demais, como nos dizem Rouxinol e Pietrocola (2004), sua aprendizagem se dá apenas pela memorização, repetição de modelos e fórmulas matemáticas, substituições de valores em cálculos automatizados, desvinculando "a linguagem matemática que essas fórmulas representam de seu significado físico efetivo" (p.22).

Além disso, a prática de ensino dessa disciplina, nessa perspectiva, ainda insiste em consolidar sua apreensão a partir de listas de exercícios extensas de maneira que os conceitos envolvidos nas questões e que deveriam ser o foco do problema, não são aprofundados por uma questão de tempo pedagógico, afinal, quando o professor opta por solicitar ao aluno a resolução exaustiva de determinados tipos de exercícios, que em sua maioria só servirão para diferenciar os estudantes que tirarão notas altas ou baixas na prova, muito do tempo que poderia ter sido dedicado à construção e compreensão do conceito fica a desejar (PIETROCOLA, 2005).

Para os estudantes, fica apenas a certeza de que a Física é uma ciência e, como tal, 
apenas os cientistas poderão ir além. Para eles, o que resta a fazer é exercitar, treinar, saber substituir valores, decorar as fórmulas para lembrar nas provas, saber os símbolos no sistema internacional de medidas, ou seja, não há mais nada para resolver, os cientistas já se ocuparam disso.

Não queremos dizer com isso que toda a culpa dessa forma desarticulada de ensino é do professor. Existe um fator histórico que não pode ser desprezado. Ver os cientistas como verdadeiros deuses faz parte de uma visão de ciência. Aquela ciência com "C" maiúsculo, que, por "saber", detém o poder de ditar regras, de ser respeitada por todos. Uma ciência que por muito tempo foi aceita como verdade absoluta. Os seus gênios, aqueles que descobriam, como se fosse num toque de mágica, os maiores mistérios do Universo, eram endeusados.

Uma contradição disso é a própria história das ciências, quando nos aprofundamos e também descobrimos que os gênios também testavam... e mais: erravam também! É na história das ciências que podemos nos aproximar do fazer da ciência, de saber que nada foi tão simples, nem para os gênios.

Assim, aproximar o nosso aluno do conhecimento físico real, possível, não é tarefa fácil para quem concebe a ciência como verdadeira, pois, se a entendemos como verdadeira, nada mais coerente do que apenas reproduzi-la e confirmá-la (LIMA, 2008). Então, as práticas em sala de aula vão se limitar a comprovar aos nossos estudantes de que a ciência estava certa. Confirmar aos nossos estudantes de que a teoria está pronta e que por isso todo conhecimento já está acabado nela. Não há mais o que pensar, o que criticar e nem o que modificar.

Para essa forma de pensar o mundo e a ciência, as memorizações e listas de exercícios são suficientes. Além disso, os conteúdos trabalhados são indispensáveis: todos eles. Independente da forma que tiver que ser apresentado ao aluno, sim, apresentado. Porque é assim que a prática tradicional da Física é vivenciada na sala de aula, a partir de aulas expositivas, apresentando a teoria (LIMA 2008). E essa teoria precisa ser "dita" aos estudantes. O livro, onde estão determinados os conteúdos previstos para o ano letivo, precisa ser "trabalhado" de capa a capa, para que nada fique de fora. Para que nenhum cientista seja desprezado.

Então pergunta-se: como mudar essa realidade? Como o conhecimento Físico que fora abordado nas páginas acima como algo real que faz parte do cotidiano do aluno pode ser ensinado? O que precisaria ser modificado? Como a Física e todo conhecimento produzido nessa área pode ficar a serviço do cidadão? Muitas são as perguntas! 
Sem sombra de dúvida, é preciso rediscutir qual Física precisa ser ensina nas escolas. Discutir qual Física pode possibilitar uma melhor compreensão do mundo. Qual Física contribuirá para a formação da cidadania. Não é tarefa tão fácil. A situação da Educação no país dificulta ainda mais, apesar de todo apelo existente nos documentos oficiais e nas pesquisas da área, quando ressalta a valorização dessa disciplina para a formação da cidadania. Como afirma Lima (2008), basta uma simples olhada para a grade de horários do Ensino Médio, quando a disciplina, a pesar de todo esse respaldo científico, tem lugar apenas em 2 aulas semanais (na grande maioria das escolas), enquanto outras disciplinas como Português e matemática gozam de 5 ou 6 aulas por semana.

Uma Física que explique porque vemos as estrelas no céu, como os corpos caem, como a Terra gira e continuamos caminhando, o que é o arco-íris, como a televisão funciona, porque a geladeira gela. Na sala de aula, poder discutir com nossos estudantes o consumo do combustível do carro, o tempo que se leva para irmos de um lugar para outro dependendo do meio de transporte que se escolhe, os gastos de energia. Enfim, são tantas questões que a Física poderia contribuir, ao invés de ficarmos exercitando fórmulas e substituindo valores.

O mais grave em toda essa discussão é o que se pretende saber depois da prática vivenciada em sala de aula. Ou seja, o que o professor, depois de dar suas 2 aulas semanais de Física, quer que os estudantes saibam? E de que maneira ele investiga isso? Essa "investigação", que poderíamos chamar apenas de "constatação" é o que a maioria dos professores chamam de "Avaliação".

Faz parte também das práticas dessa disciplina uma forma tradicional de avaliar seus estudantes. Que não deixa também de ser coerente com as concepções de mundo e de conhecimento que estão envolvidas nessa situação. Se a ideia de que o conhecimento está pronto e que nada mais deve ser modificado, sua forma de avaliar perpassa por práticas de constatação. Como afirma Lima (2008), todas as listas de exercícios, todas as fórmulas apresentadas em aula são trazidas para esse momento, que é pontual, após o processo de ensino, através das chamadas "provas", que comprovam se o aluno tem a capacidade de reproduzir o conhecimento ou não.

Então, esse é outro ponto crucial que deve ser modificado quando nos referimos ao conhecimento Físico: a sua forma de avaliar. Essa deveria está a serviço de uma maior compreensão desse conhecimento. Deveria auxiliar o aluno a compreender o que ele já sabe para entender o novo. Por isso, o ponto de partida de toda aprendizagem deveria ser o que o aluno já sabe e o que ele quer saber ou precisa saber, de acordo com sua realidade 
e não do que o livro ou outras pessoas acham que deveriam.

Não estamos considerando aqui que os conteúdos produzidos e ensinados da Física são desprezíveis. De maneira alguma. Apenas chamamos para a reflexão de como esses conteúdos são escolhidos. É sabido que muitos dos conceitos discutidos em sala de aula e que parecem não fazer parte da vida dos estudantes, fazem parte sim. Todos os professores de Física ensinam aos seus estudantes o movimento uniformemente variado, por exemplo, que tem a ver com os com as distâncias percorridas e a velocidade, que vivenciamos o tempo todo. Então, não é uma questão de se excluir conteúdos, mas de ressignificá-los.

Ressignificar um conhecimento na sala de aula, significa incluir o aluno, ou seja, “feitas as investigações, abstrações e generalizações potencializadas pelo saber da Física, em sua dimensão conceitual, o conhecimento volta-se novamente para os fenômenos significativos" (BRASIL, 2002, p. 23). Algo que tenha sentido para o aluno para que possa se apropriar e saber fazer uso em sua vida cotidiana, de modo que esse saber construído possa servir, no futuro, de base de outros novos conhecimentos.

Portanto, é importante destacar que “o conhecimento da Física 'em si mesmo' não basta como objetivo, mas deve ser entendido sobretudo como um meio, um instrumento para a compreensão do mundo" (p. 23), especialmente no Ensino Médio, que é um momento inicial de muitas discussões e abstrações do conhecimento Físico. É nessa etapa de escolarização que o conhecimento em Ciências da Natureza vai se especificando e favorecendo o sentido conceitual da Física.

Considerando que estamos em um novo momento da história, onde as tecnologias ganham espaços nunca antes pensado e a Física como aliada dessa nova realidade que os nossos estudantes fazem parte, faz-se necessário promover estudantes autônomos, criativos, centrados em novas perspectivas de vida e de realidade, críticos e protagonistas. Não é com práticas conservadoras que vamos alcançar tal objetivo. Mas, sim, com formas de abordagens acerca do conhecimento Físico que promova esse novo aluno e futuro profissional, que saiba lidar, independente da carreira que siga, com as inovações e com as transformações que o mundo lhe oferece. Uma prática que vai além de conteúdos, mas que se busque formar estudantes que saibam articular saberes.

\section{Conclusões}

Diante do exposto, observamos a importância de um ensino de Química contextualizado, que considere suas relações com o cotidiano dos estudantes. 
Ressaltamos que a Química em sua maneira própria de ensino e avaliação, que melhor discute e constrói o conhecimento nessa área. Essa construção, mais do que a simples memorização, requer do aluno também habilidades desenvolvidas. Mas essas habilidades não se limitam apenas às questões conceituais. É preciso que seja desenvolvido também o respeito mútuo, a lealdade, a tolerância, assim o ensino da Química será muito mais que fórmulas, misturas, substâncias, será um auxiliar para o desenvolvimento de valores humanos.

Esse ensino deve primar por uma prática avaliativa que garanta a construção de saberes que os estudantes possam articular e utilizar na vida cotidiana. Sabemos, porém que esse ensino ainda está muito longe de ser praticado na maioria das escolas do Ensino Médio do Brasil, mas ressaltamos a necessidade de que sejam repensadas, para que o ensino de Química possa resgatar o seu papel de uma ciência experimental, mas que forma cidadão.

\section{Referências}

ANDRADE, R. S. ; SALES, E. S. ; LIMA, K. S. . A avaliação no ensino da Química: um estudo com professores em formação. In: VIII Congresso Internacional de Educação da UNISINOS e III Congresso Internacional de Avaliação, 2013, Gramado/RS, 2013. Anais Congresso Internacional de Educação da UNISINOS e III Congresso Internacional de Avaliação, 2013, Gramado/RS. Sem titulo, 2013.

BRASIL, Ministério da Educação, Secretaria de Educação Média e Tecnológica. PCNs+ Ensino Médio: orientações educacionais complementares aos Parâmetros Curriculares Nacionais. Ciências da Natureza, Matemática e suas Tecnologias. Brasília: MEC, SEMTEC, 2002.

GUBA, E. G.; LINCOLN, Y. S. Fourth generation evaluation. Newbury Park, London, New Delhi: Sage, 1989.

HOFFMAN, J. Avaliação mediadora: uma prática em construção da pré-escola à universidade. Porto Alegre: Mediação, 2001.

LIMA, K. S. Compreendendo as concepções de avaliação de professores de física através da teoria dos construtos pessoais. Recife, 2008. 163 p. Dissertação (Mestrado em Ensino das Ciências). Pró-Reitoria de Pesquisa e Pós-Graduação, Universidade Federal Rural de Pernambuco, 2008.

MONTEIRO, I. G. S. ; SALES, E. S. ; LIMA, K. S. . Experimentos em sala de aula: minimizando barreiras no ensino da Química In: VII Colóquio Internacional Educação e Contemporaneidade, 2013, São Cristóvão - SE. Anais do Colóquio Internacional Educação e Contemporaneidade, 2013.

PIETROCOLA, M. ; MAGALHÃES JÚNIOR, C. A. O. Políticas educacionais e história da formação e atuação de professores para a disciplina de ciências. In: V ENCONTRO 
NACIONAL DE PESQUISA EM EDUCAÇÃO EM CIÊNCIAS. Atas do V ENPEC. São Paulo, 2005.

REGO, A.M.C ; ARAÚJO, R.M. ; VIANA, K.S.L. AS GERAÇÕES DA AVALIAÇÃO E SUAS RELAÇÕES COM O ENSINO DA QUÍMICA. In: I Simposio Latinoamericano de Intercambio sobre Ensiñanza de la Química, 2014, La Plata - Argentina. Anais do I Simposio Latinoamericano de Intercambio sobre Ensiñanza de la Química, 2014.

SALES, E. S. ; MONTEIRO, I. G. S. ; LIMA, K. S. . Formação de professor, diretrizes da Educação brasileira para o ensino de Química e Avaliação: saberes docentes essenciais à formação docente. In: VII Colóquio Internacional Educação e Contemporaneidade, 2013, São Cristóvão - SE. Anais do Colóquio Internacional Educação e Contemporaneidade, 2013.

SALES, E. S. ; LIMA, K. S. . Formação de professor e avaliação: um estudo sobre as contribuições da formação docente para prática avaliativa. In: $53^{\circ}$ Congresso Brasileiro de Quimica, 2013, Rio de Janeiro/RJ. Anais Congresso Brasileiro de Quimica, 2013. 